\title{
What are the sexual and reproductive health needs of adolescents in Ghana's slums?
}

Selina F. Esantsi

Population Council

Gloria Quansah Asare

Placide Tapsoba

Population Council

Follow this and additional works at: https://knowledgecommons.popcouncil.org/departments_sbsr-rh

Part of the Demography, Population, and Ecology Commons, Family, Life Course, and Society Commons, Gender and Sexuality Commons, Inequality and Stratification Commons, International Public Health Commons, Maternal and Child Health Commons, and the Women's Health Commons How does access to this work benefit you? Let us know!

\section{Recommended Citation}

Esantsi, Selina F., Gloria Quansah Asare, and Placide Tapsoba. 2015. "What are the sexual and reproductive health needs of adolescents in Ghana's slums?" STEP UP Evidence Brief, October. Accra: Population Council. 

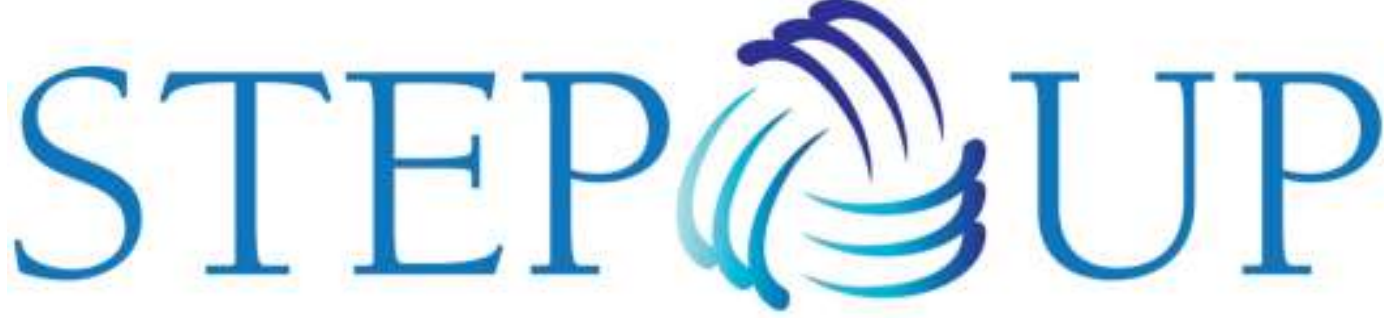

STRENGTHENING EVIDENCE FOR PROGRAMMING ON UNINTENDED PREGNANCY

October 2015

\section{What are the sexual and reproductive health needs of adolescents in Ghana's slums?}

\section{INTRODUCTION}

While there is an abundance of information on adolescent sexual and reproductive health (ASRH) in general, few studies have focused on the needs of specific groups of adolescents, such as adolescents living in a particular area. Accordingly, there is little known about the extent or variations in these needs of adolescents in Ghana, including those who live in slums. Moreover, youth-driven health programs are still being implemented in these areas, often with little understanding of the circumstances and needs of the young people they target (Annabel et al. 2007).

STEP UP generates policy-relevant research to promote an evidencebased approach for improving access to family planning and safe abortion.

We work in Bangladesh, northern India, Ghana, Kenya, and Senegal.

Population Council Coordinating Partner

African Population and Health Research Center

icddr,b

London School of Hygiene and Tropical Medicine

Marie Stopes International

Partners in Population and Development

Funded by

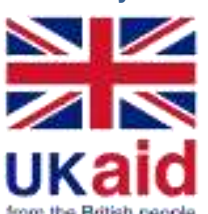

To address this need for quality evidence on the SRH needs of adolescents in slums, the STEP UP project conducted a study in four slum settings in Brong Ahafo and Greater Accra regions of Ghana. This evidence can be used to improve ASRH programming so that it better meets the needs of slum-dwelling adolescents.

\section{About the study}

The overall objective of the study was to generate evidence on the knowledge, perceptions and practices surrounding ASRH within selected slum communities in Ghana. The specific objectives were:

1. To assess the reproductive health knowledge, behaviour and perceptions of adolescents in the slum settings

2. To examine the perceptions of parents, guardians and community members regarding adolescent sexual and reproductive health.

\section{METHODOLOGY}

The study team used data from a cross-sectional study that employed both qualitative and quantitative methods to assess ASRH knowledge and perceptions of adolescents, their parents/guardians and community opinion leaders. Data was collected in March 2013 in four urban slums in Ghana: two (2) in the Greater Accra Region (Nima and Ashiaman) and two (2) (Sunyani East and Atebubu) in the Brong Ahafo Region.

\section{KEY POINTS}

- There is a need for a welldesigned, comprehensive sex education curriculum appropriate for each educational level that is taught by well-trained individuals; gender differences in SRH knowledge, attitudes and practices should be taken into account in the curriculum development process.

- Interventions that address sexual coercion and violence should be an integral component of current adolescent reproductive health programs. Such interventions should empower adolescents to know what coercion is, signs of violence as well as where to seek services.

- There is need to involve all stakeholders including parents/guardians and community leaders in addressing adolescent SRH needs. This will, in turn, enhance community participation and address cultural and societal barriers and inhibitions to the optimal realization of adolescent sexual and reproductive health. 
Study Subjects

- A total of 1,303 adolescents aged 13-19 years were recruited. More than half of the adolescents (58\%) were female. Adolescents aged 18-19 years comprised the highest proportion $(40 \%)$ of the sample ( $42 \%$ of males and $38 \%$ of females).

- A total of 626 parents/guardians were interviewed. About $66 \%$ of those interviewed were the biological parents of the adolescents. Other guardians included grandparents $(10 \%)$ and uncles or aunties (15\%).

- A total of 42 community opinion leaders comprising chiefs, assemblymen (local government authority representatives), farmers, traders, Imams and teachers were recruited. Of these, $62 \%$ were male.

\section{KEY FINDINGS}

\section{Profiles of Adolescents}

- Nearly all (96\%) of the adolescents had ever attended school, with a significantly higher proportion of males compared to females having ever attended school $(99 \%$ and $95 \%$ respectively).

- Slightly over half of the adolescents $(57 \%)$ had completed primary education. Among respondents who had ever attended school, $75 \%$ were still in school $(78 \%$ of males and $74 \%$ of females). They spent about a third of their day in school (32\% for the males and 30\% for females).

- Over half (55\%) were Christian, while $43 \%$ were Muslim.

- Nearly all (97\%) had at least one living parent. Among those with at least one living parent, $70 \%$ reported that a parent was living with them in the same household.

- Slightly over one-quarter (26\%) had ever worked for pay. Those who worked earned an average of $\mathrm{GH} \phi 40$ per week. They were engaged in sales ( $41 \%$ street hawking or managing stores), services (30\% fetching water, tending to animals, or laundry) and technical services (22\% mechanics or dressmaking). It is also worth noting that female adolescents spent relatively more time on unpaid work (19\%) compared to males (10\%).

\section{Where do adolescents get SRH information?}

About $79 \%$ of males and $64 \%$ of females indicated that they currently receive information on puberty from their school teachers. School teachers also provide $74 \%$ of males and $65 \%$ of females with information on pregnancy and sexual and reproductive health. This indicates that the school system does provide adolescents with some information on sexual maturation and related issues.

However, many adolescents - primarily girls - would prefer to obtain SRH information from their mothers. On the topic of puberty, $35 \%$ of females and $18 \%$ of males preferred information from their mothers; on the topic of reproductive health, $29 \%$ of females and $14 \%$ of males did.

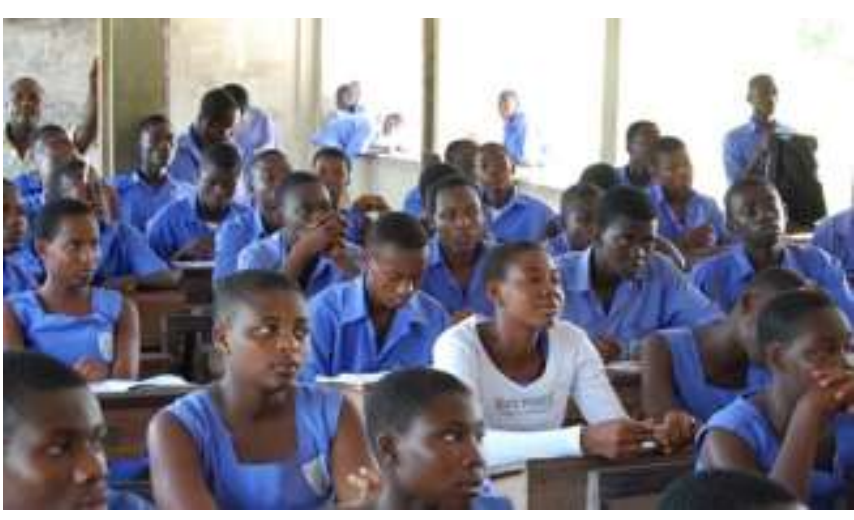

Adolescents Photo credit: www.pen-international.org

When asked if they would want more in-school classes on reproductive health, $80 \%$ (both sexes) responded in the affirmative.

Interestingly, almost half of the adolescents ( $49 \%$ of males and $45 \%$ of females) obtained information on relationships principally from their friends. Yet some (a higher proportion of females than males) preferred to obtain information on relationships from their mothers (29\% and $15 \%$ respectively).

The contribution of mass media as a source of SRH information for the adolescents is conspicuously non-existent. However, their relevance cannot be discounted, as newspapers, magazines, radio, television and the internet are sources that are closely associated with literacy and urban residence, which is where the slum study sites were located.

\section{Sexual activity of adolescents}

How many adolescents are sexually active? One-third of the adolescents (33\%) had ever had sexual intercourse, with no significant difference between male and female respondents (32\% and $34 \%$ respectively). The proportion of adolescent girls in the study that had ever had sexual intercourse is similar to the proportion found from the 2008 GDHS data -- 37\% (GSS et al., 2009). That data from five years apart show that the same proportion of adolescents are sexually active suggests that existing ASRH programmes may not be reaching adolescents, and should be reviewed to make sure they are having the desired impact.

How old are they?: The proportion of adolescent males that had ever had sexual intercourse was highest among those aged 1819 years and lowest among those aged 15 years and below ( $47 \%$ and $8 \%$ respectively). The proportion of adolescent girls that had ever had sexual intercourse was more than twice as high among those who had never attended school than among those who had ( $73 \%$ and $32 \%$ respectively). 
What factors influence whether adolescents are having sex? Several factors correlated with whether adolescents had ever had sex, including school attendance, parental involvement, work history, and location.

The proportion of adolescents who had ever had sexual intercourse was also highest among those whose parents were not living in the same household than among those with at least one parent living in the household. Further, the proportion that had ever had sexual intercourse was more than twice as high among those who had ever worked for pay than among those who had not (51\% and $22 \%$ respectively). Additionally, the proportion of adolescent girls who had ever had sex was highest in Brong Ahafo and lowest in the Greater Accra region ( $41 \%$ and $28 \%$ respectively).

Unplanned sex, forcible sexual contact, \& transactional sex: Slightly more than one-third of adolescents $(36 \%)$ reported that their first sexual intercourse was unplanned.

About one-fifth - significantly more females than males reported that they had ever been forcibly touched on their private parts (24\% and $13 \%$, respectively). Among respondents who had ever had sexual intercourse, 15\% reported having experienced forced sex ( $12 \%$ of males and $16 \%$ of females).

In addition, $5 \%$ of the adolescents who had ever had sexual intercourse reported having ever paid money or gifts for sex ( $9 \%$ of males and $2 \%$ of females). Similarly, $4 \%$ of adolescents who had ever had sexual intercourse reported receiving money or gifts for sex (approximately $4 \%$ of both males and females).

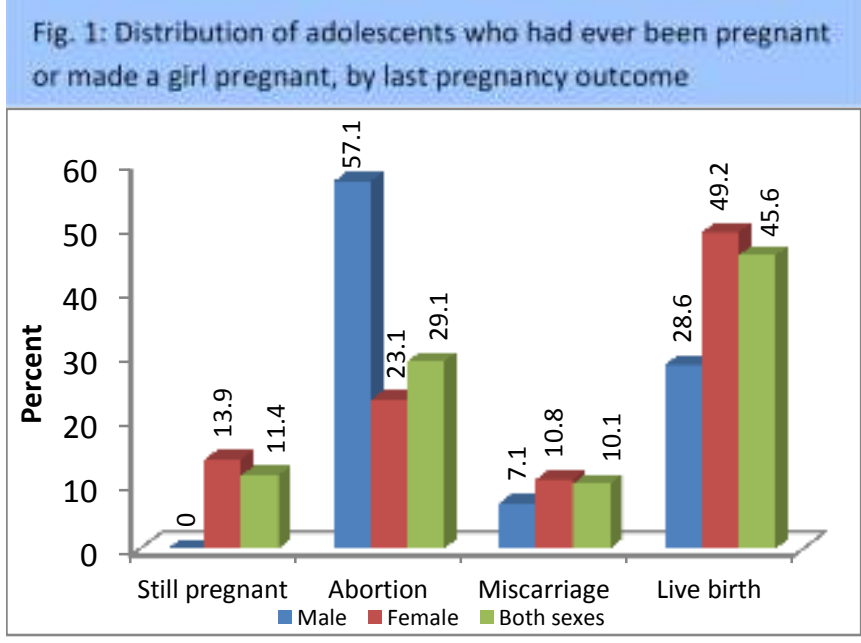

\section{Pregnancy Experience and Outcomes}

Among adolescents who had ever had sexual intercourse, $8 \%$ of the males reported having ever made a girl pregnant while $26 \%$ of the females reported having ever been pregnant.
The proportion of girls that had ever been pregnant was significantly higher in Brong Ahafo than in the Greater Accra region ( $31 \%$ and $20 \%$ respectively), which is consistent with the fact that more girls had ever had sex in the Brong Ahafo region (see 'sexual activity of adolescents'). This rate was also significantly higher among adolescent girls who were not attending school as compared with those who were attending school at the time of interview (34\% and 14\% respectively). This is consistent with the view in the literature that keeping girls in school positively influences their SRH outcomes.

For the majority of adolescents who had ever been pregnant or made a girl pregnant $(76 \%)$, the most recent pregnancy was not wanted ( $86 \%$ of males and $74 \%$ of females). In addition, $57 \%$ of the males who had ever made a girl pregnant and $23 \%$ of the girls who had ever been pregnant reported that the last pregnancy resulted in abortion (Figure 1).

\section{Perceptions of parents \& community opinion leaders}

Parents: Although the majority (95\%) of parents/guardians were not aware of organizations which provide SRH services to adolescents, nine out of ten $(91 \%)$ were willing to allow their adolescents to receive such services. Further, only $20 \%$ had knowledge of the existence of any health facilities. Less than $10 \%$ disapproved of the provision of SRH services to adolescents. A high proportion (97\%) of guardians wanted SRH information to be provided in schools. About $66 \%$ indicated that they themselves needed more information especially on family planning, contraceptive use, STIs, and HIVIAIDS to enable them have more meaningful discussions with their adolescents.

Community opinion leaders: Community opinion leaders believed that the increasing numbers of teenage pregnancies and adolescent commercial sex workers is evidence that most adolescents in their communities are sexually active:

"Teenage pregnancy is increasing in the community. The adolescents are having sex both days and nights...Majority in the ages 13, 14 to 19 are getting pregnant and they take drugs to abort the pregnancy which ends up in death or destruction of their womb. ... Some girls give birth to about two without knowing the baby's father.... These babies are left in the care of the adolescents' parents... These babies also grow and start behaving like their adolescent parents and these social vices continue." FGD, Atebubu

Some community opinion leaders approved of the use of contraceptives by adolescents:

"It is true that our religion frowns upon it, but rather than having to do it unprotected and come home with an unwanted pregnancy or be at risk of sexually transmitted infections we will take it like that... They say prevention is better than cure, so it is better for them to prevent than to become pregnant and attempt to abort which can cost them their lives..."

FGD, Sunyani 
“...Teachers do not teach details about reproductive health, they only teach about effect of sexually transmitted diseases... the adolescents should be given these services to protect them from unwanted pregnancy....the information and services if given to the adolescents is good because it will broaden their knowledge and prevent them from engaging in activities that will destroy their future...." FGD, Atebubu

\section{CONCLUSION}

Most of the study findings are consistent with other studies on general adolescent sexual behaviour; there are no significant variations in adolescent SRH knowledge and practices among those living in the slums versus in other areas of the country. This study's findings also re-enforce the importance of education in the lives of adolescents as it has a significant impact on age at first sex and all of the associated impacts on adolescents' lives.

Two broad issues emerged across all the respondents:

- There is an urgent need for ASRH education to equip youth with necessary skills for informed decision making.

- There is demand by both parents and adolescents for quality parent-adolescent communication. This should be improved through intervention programs which focus on building SRH knowledge and communication skills of both youth and their parents.

\section{REFERENCES}

1. Erulkar Annabel S., Matheka James K. 2007. Adolescence in the Kibera slums of Nairobi, Kenya.

2. Ghana Statistical Service (GSS), Ghana Health Service (GHS), and ICF Macro. 2009. Ghana Demographic and Health Survey 2008. Accra, Ghana: GSS, GHS, and ICF Macro.

3. Koenig MA, Zablotska I, Lutalo T, Nalugoda F, Wagman J, Gray R. Coerced first intercourse and reproductive health among adolescent women in Rakai, Uganda. Int Fam Plan Perspect. 2004 Dec; 30 (4):156-63. PubMed PMID: 15590381.

4. United Nations Educational, Scientific and Cultural Organization (UNESCO). 2009. International Technical Guidance: An EvidenceInformed Approach for Schools, Teachers and Health Educators, Vol. II. Paris: UNESCO.

\section{Suggested citation}

Selina F. Esantsi, Gloria Quansah Asare, Placide Tapsoba. 2015.

"What are the sexual and reproductive health needs of adolescents in Ghana's slums?" STEP UP Evidence Brief, October 2015. Accra:

Population Council.
“...Teachers do not teach details about RH, they

only teach about the effects of STIs... adolescents should be given these services to protect them from unwanted pregnancy.... information and services, if given to the adolescents, is good because it will broaden their knowledge and prevent them from engaging in activities that will destroy their future...." FGD, Atebubu

\section{DISCUSSION}

- Lack of adequate and quality SRH information is one of the major barriers to adolescent's access to SRH services. Three in four adolescents in this study indicated that they want more classes on $\mathrm{SRH}$ and their parents have also expressed the need for a more comprehensive SRH education in schools. This suggests the need for a review of the current SRH curriculum especially since literature from the United Nations Educational, Scientific and Cultural Organization ((UNESCO) UNESCO 2009) indicates that intensive and prolonged curriculumbased sexual education show promising results on preventing adverse outcomes of adolescent $\mathrm{RH}$ challenges.

- A sizable proportion of the adolescents reported engaging in transactional sex and experiencing sexual coercion. Coerced sex has been associated with a range of negative health and reproductive outcomes (Koenig et al., 2004) and transactional sex has been identified as one of the risk factors for increased vulnerability to HIV. This suggests a need to include information on avoiding engaging in transactional sex, and perpetrating coerced sex.

- Half of the adolescents interviewed indicated they received most of their information on relationships from their friends. This could mean that adolescents are gaining limited abilities to negotiate safe sex. Through both the home and school system, adolescents should be given support for developing the skills to negotiate consensual and non-exploitative relationships. 